\title{
GRUNDTVIG-LITTERATUR 1950
}

\author{
En bibliografisk oversigt ved cand. mag. Steen Johansen
}

Oversigten fortsætter den tilsvarende oversigt over Gr.-Iitteratur 1945-49 i Grundtvig-Studier 1951, 115-130 og er anlagt ganske efter dennes mønster, naar undtages, at enkelte grupper her er blevet sammendraget af pladshensyn. Saavel i denne oversigt som i den forrige er udeladt omtale f. eks. af antologier, hvori Gr.-tekster kun udgør en mindre del, grundtvigske sang- og salmebøger, (populære) skildringer af Gr.s liv i leksika eller andre mindre haandbøger, skolelitteraturhistorier olgn., litteratur om Vartov, om salmebogssagen, den meste højskolelitteratur. Der sluttes med nogle tilføjelser og rettelser til forrige oversigt.

\section{Bibliografi.}

Steen Johansen: Bibliografi over N. F. S. Gr.s Skrifter. II. 1837-49. 1950. Anm. bl. a. af Søren Holm i Aalborg Stiftstid. 3. juni 50 og i Bogens Verden 1951, s. 311, og af Henning Høirup i Fyns Tid. 2. juli 50.

\section{Udgaver, tekstudgivelser.}

Grundvig. I Udtog ved og med Indledning af Hal Koch. 1950. (I Martins Forlags serie: Udødelige Tanker.)

Anmeldtes bl. a. af flg.: J. Bukdahl i Politiken 14. dec. 50, H. Kvist i Flensborg Avis 4. nov. 50, Peter P. Rohde i Information 18. okt. 50, Paul V. Rubow i Berl. Aftenavis 23. sept. 50.

Om Gr.s efterladte papirer.

Helge Toldberg: Gr.s efterladte Papirer. - Nationaltid. 27. juni 50.

\section{Samlede fremstillinger, karakteristikker.}

Hal Kochs Indledning s. 7-63 i det under II omtalte udtog.

H. W. Eppelsheimer: Handbuch der Weltliteratur II, 1950 (Frankfurt am Main), 33. - Yderst kortfattet.

\section{Specialia vedr. Gr.s liv og forfatterskab.}

a. Slægt, slægtninge.

Gr.s sønnesøn, fhv. overbibliotekar Vilhelm Grundtvig døde 29. april 1950. Blandt de fremkomne mindeartikler kan nævnes: Gustav Albeck i Jyllandsposten 2. maj 50 og samme i Gr.-Studier 1950, 96-99, Em. Sejr i Aarhuus Stiftstid. 22. april 50 og samme i Nord. Tidskr. för Bok- og Biblioteksväsen $1950,71-74$. 
b. Privatliv, personlig udvikling.

Carl Jorgensen: Minder om N. F. S. Gr.s Barndomsaar i Thyregod Præstegaard. - Ribe Stifts Aarbog 1950, 34-51.

Gustav Albeck: Den sorte Skole hædrer Gr. - Jyllandsposten 24. juni 50. Aage Bertelsen: Gr.s Syn paa Aarhus Latinskole. Aarhuus Stiftstid. 24. juni 50. Steen Johansen: Gr. og teatret. Et par bemærkninger i tilknytning til Robert Neiiendams afhandling [ $\mathrm{J}$ : om samme emne i R. N.: Gennem mange Aar, 1950, udvidet optryk af en afh. fra 1940.] Gr.-Studier 1950, 100-102. Frode Aagaard: Gr. under treaarskrigen. - Aalborg Amtstid. 24. juli 50.

c. Litterært ell. personligt forhold til enkeltpersoner - eller disses forhold til Gr.

M. Björkquist: Gr. och Geijer. Men särskild hänsyn till historiesynen. Dansk Udsyn 1950, 269-284.

Th. Krogholt: Gr.s betydning for Jakob Knudsen. - Menighedsbladet 15. og 22. jan. 50.

Marie Christensen: Peter Larsen Skræppenborg. - Vartovbogen 1950, 21-42. - Heri ogsaa om L.s berøring med Gr.

P. G. Lindhardt: Morten Pontoppidan. I. 1851-1893. Aarhus 1950. Heri ogsaa om P.s forhold til Gr.

»Der studeres flittigt $\mathrm{i}$ danske præstegaarde«. [Interview $\mathrm{m}$. biskop dr. phil. C. I. Scharling i] Krist. Dagbl. 26. febr. 50. - Heri Sch. om sit forhold til Gr.

Peter Schindler: Vejen til Rom. 1950. - Heri fortæller forf. 112-116, $118 \mathrm{ff}$. , om sin ungdoms forhold til Gr. og grundtvigianismen, som atter førte ham over i katholicismen. Jvf. hertil P. Augustinus i Menighedsbladet 30. april 50 .

d. Teologiske, filosofiske og psykologiske sporgsmaal vedr. Gr.

(Alfabetisk efter forff.)

K. C. Holm: Gr.s menighedstanker. - Menighedsbladet 29. okt. 50.

Herm. Madsen: Gr. og malerkunsten. - Fyns Tid. 11. maj 50.

Regin Prenter: Gr.s og Einar Billings syn på folkekirken. - Viborg Stifts Aarbog 1949. 1950, 128-144.

C. J. Scharling: Kristi Genkomst og Kødets Opstandelse. Det eskatologiske hos Gr. - Gr.-Studier 1950, 7-56.

e. Litterære og filologiske behandlinger af dele af Gr.s forfatterskab bortset fra salmerne.

1.

(Alfabetisk efter forff.)

Gustav Albeck: Gr.s Forsøg som Bibeloversætter.

Bidrag til den danske Bibels Historie. Festskrift. Aarhus 1950. 148-174. Erik Møller: Gr. som Samtidshistoriker. 1950.

Anmeldt bl. a. af flg.: K. Gjesing-Pedersen i Nationaltid. 17. dec. 50, Uffe Hansen i Højskolebl. 13. apr. 51, G. Helms i Fyns Venstrebl. 1. okt. 50, H. Høirup i Fyns Tid. 3. okt. 50, Hal Koch i Politiken 9. okt. 50, W. 
Michelsen i Gr.-Studier 1951, 98-103 og i Gymnasieskolen 1951, 247 ff., V. Riisager i Krist. Dagbl. 2. nov. 50, Peter P. Rohde i Information 18. okt. 50, Paul V. Rubow i Berl. Aftenavis 23. sept. 50, F. Sohr i Præsteforeningens Blad 13. okt. 50.

Helge Toldberg: Gr.s symbolverden. 1950. [Disputats.] Skrifter udg. af Gr.Selskabet. II.

Anmeldtes bl. a. af flg.: Den Gamle ( $\mathrm{O}$ J. Chr. Bay) i Dannevirke (udg. i Cedar Falls, Iowa), 30. aug. 50, Søren Holm i Aalborg Stiftstid. 8. aug. 50, Mogens Haugsted i Bogens Verden 1951, s. 350, H. Høirup i Fyns Tid. 2. juli 50, i Højskolebl. 21. juli 50, i Menighedsbl. 6. og 13. aug. 50, Svend Johansen i Selskab for nordisk filologi. Ãrsberetning for 1948 -49-50, [1951], 35-37 (»Det teoretiske grundlag for H. T.s disputats »Gr.s symbolverden««), W. Michelsen i Gymnasieskolen 1950, 406-408, P. Riemann i Menighedsbl. 1. og 8. apr. 51, A. Riishøj i Dansk Tunge 1950, 197-202, P[eter] P. R[ohde] i Information 27. juni 50, Paul V. Rubow i Berl. Aftenavis 16. aug. 50, Fr. Schrøder i Præsteforeningens Blad 1950, 546-548, H. Stangerup i Fyns Stiftstid. 8. aug. 50 og Jydske Tid. 20. sept. 50, V. Svanberg i Stockholms-Tidningen 13. aug. 50.

2.

(Kronologisk efter de behandlede skrifter af Gr.)

Aage Jensen: Påskeliljen. Gr.s skønne digtning om begivenhederne ved Herrens Grav. [1817.] — Indre Missions Tidende 1950, $182 \mathrm{f}$.

H. Høirup: Løven askegraa. Gr.s digte om Istedslaget. [1850.] - Krist. Dagbl. 18. aug. 50 .

Aug. F. Schmidt: Trøst i Sorg. [Om Kærmindesangen.]. - Aarhus Amtstidende 5. aug. 50 .

Ernst J. Borup: Oplysninger til »Danmark om hundrede Aar《. Vartovbogen 1950, 65-73. - Selve det nævnte digt af Gr. (fra sept. 1850), aftrykt s. st. $57-64$.

C. P. O. Christiansen: Omkring Gr.s Digt »Danmark om hundrede Aar«. Vartovbogen 1950, 74-100.

Roar Skovmand: Danmark i hundrede år.

Dansk Udsyn 1950, 17-26. - (Betragtninger paa grundlag af førnævnte digt af Gr. 1850).

\section{f. Gr.s salmer.}

1.

Om salmerne i alm.

(Alfabetisk efter forff.)

Uffe Hansen: Gr.s sakramentsyn og hans salmer. - Menighedsbladet 8. og 15. okt. 50.

Magnus Stevns: Fra Gr.s Salmeværksted. Udg. af Henning Høirup og Steen Johansen. 1950. Skrifter udg. af Gr.-Selskabet. III.

Anmeldt bl. a. af flg.: S. A. (5: Sune Andresen) i Dansk Tunge 1950, 219, Johs. Blauenfeldt i Bogens Verden 1951, s. 351, Ernst J. Borup i Højskolebl. 9. marts 51, H. Høirup i Fyns Tid. 19. sept. 50, H. Kvist i Flensborg Avis 4. nov. 50, W. Michelsen i Gymnasieskolen 1951, 247 ff., P. M. 
Mitchell i Scandinavian Studies, Aug. 1951, 163 f., Niels Møller i Gr.-Studier 1951, 95-98, V. Riisager i Krist. Dagblad 2. nov. 50, Peter P. Rohde i Information 18. okt. 50, Paul V. Rubow i Berl. Aftenavis 16. sept. 50, H. Toldberg i Nationaltid. 8. sept. 50.

G. Tolderlund-Hansen: Juletoner hos G. - Fyns Tid. 21. dec. 50.

\section{2.}

Enkelte salmer.

(Alfabetisk efter hver salmes forstelinie.)

Th. Balslev: Guds Kildevæld. - Vartovbogen 1950, 10-20. (Om »Alle mine Kilder skal være hos dig! «)

Om forfatterskabet til "Saa vil vi nu sige hverandre Farvel" se Astrid Danielsen i Menighedsbl. 14. maj 50 og Uffe Hansen s. st. 4. juni 50. Axel Rosendal: Velkommen igen - Roskilde Stiftsblad 1950, 89-94.

g-i. Gr. og England, Gr. som politiker, Gr. og Sønderiylland.

P. G. Lindhardt: Gr. and England. - The Journal of Ecclesiastical History Vol. I, 1950, 207-224.

Erik Moller: Gr. i 1848-50. - Gr.-Studier 1950, 57-95.

Troels Fink: Gr. og Sønderjylland. - Jyske Samlinger. Ny rk. I, 1950, 59-71.

k-m. Gr. som folkeopdrager, Gr. og Norden etc., Gr. og det menneskelige, det sociale.

(Alfabetisk efter forff.)

Sune Andresen: Gr.s syn på mennesket. - Menighedsbladet 6. aug. 50.

Poul Engberg: N. F. S. Gr. Ein nordischer Volkserzieher. Stuttgart 1950. (I serien »Gedanken führender Pädagogen «.)

K. C. Holm: Gr.s Syn paa Menneskeliv og Kristendom. - Nationaltidende 26. nov. 50 .

Sven Nielsen: Gr.s Göteborgtanke. - Aalborg Amtstidende 19. juni 50. Hans Thysen: Gr.s syn på mennesket. - Menighedsbl. 23. juli 50.

Den i forrige oversigt nævnte bog af Fr. Skrubbeltrang: Den danske Folkehøjskole, 1946, er siden udkommet i engelsk forkortet bearbejdelse (The Danish Folk High Schools. Copenhagen. Det danske Selskab. 1947) og i tysk oversættelse (ved Wilh. Krämer), kun ringe forkortet (Die Volkshochschule (Handbücher der dänischen Gesellschaft), Kbh. 1950).

$\mathrm{n}-\mathrm{p}$. Grundtvigianismen, Gr. og missionen, grudtvigianere etc.

N. E. Asmussen: Er Indre Mission ved at slå ind på den grundtvigske linje?

- Indre Missions Tidende, 1950, 239. Hertil svar af C. Bartholdy $251 \mathrm{f.}$, jfr. ogsaa Præsteforeningens Blad 2. juni 50.

Holger Brondsted: „En bette Grundtvigianer«. - Dansk Kirkeliv medens Tiderne skifter, 1950, 35-41.

Henning Hoirup: Har Gr. noget at sige vor Tid? - Vejle Amts Folkeblad 11. dec. 50 og Sorø Amtstid. 10. jan. 51.

- Grundtvigianismen i Norge. - Fyns Tidende 11. dec. 50. 
Steen Johansen: Hvor gammelt er ordet »grundtvigianer«? - Højskolebladet 25. aug. 50.

Erik H. Knudsen: Otto Møllers kritik af den folkelige grundtvigianisme. Dansk Udsyn 1950, 37-46.

P. G. Lindhardt: Morten Pontoppidan. I. 1851-1893. Aarhus 1950.

Ikke alene om P.s personlige forhold til Gr. o.s.v., men også, med forf.s ord, samtidig »i nogen grad en studie over den »yngre《 grundtvigianisme og således et bidrag til dansk kirkehistorie $i$ slutningen af forrige århundrede«.

Niels Petersen: Grundtvigsk tilbageblik og - fremblik. - Krist. Dagbl. 20. og 22. nov. 50 .

Om den grundtvigske præst $P$. N. Petersen i Alslev kan læses i Johs. FogPetersen: Præstegårdsliv i Firserne, tr. i Præstegaardsliv. Minder fra gamle Præstegaarde. Red. af Ernst Fr. Hansen. [Første Samling], 1949, 62-78.

q. Grundtvig-Selskabet og dets publikationer.

Gr.-Selskabet har i 1950 udsendt flg. skrifter:

Grundtvig-Studier 1950. Under Redaktion af Henning Høirup.

Anmeldt bl. a. af flg.: S. A. (5: Sune Andresen) i Dansk Tunge, 1950, 218 f., Johs. Blauenfeldt i Bogens Verden 1951, s. 350, Ernst J. Borup i Højskolebl. 1. dec. 50, G. Helms i Fyns Venstrebl. 1. okt. 50, Th. Krøgholt i Fyns Tid. 6. okt. 50, H. Kvist i Flensborg Avis 4. nov. 50, W. Michelsen i Gymnasieskolen 1951, 247 ff., V. Riisager i Krist. Dagbl. 2. nov. 50, Peter P. Rohde i Information 18. okt. 50, Paul V. Rubow i Berl. Aftenavis 16. sept. 50.

I Gr.-Selskabets serie: 》Skrifter udgivet af Grundtvig-Selskabet« er i 1950 udsendt:

Bd. II: Helge Toldberg: Gr.s symbolverden. - Anmeldelser, se her foran under III. e. 1.

Bd. III: Magnus Stevns: Fra Gr.s Salmeværksted. Udg. af Henning Høirup og Steen Johansen. - Anmeldelser, se her foran under III.f. 1.

\section{Tilføjelser til oversigten over Gr.-litteratur 1945-49 \\ i Gr.-Studier 1951, 115-130.}

Ad II: Bd. IV (1949) af den nye Sangværk-udgave er, sammen m. bd. V (1951), anmeldt af Fred. Schrøder i Højskolebl. 21. sept. 51.

»Gr.s Erindringer . . « ogsaa anmeldt af E. J. i Göteborgs Handelsoch Sjöfarts-Tidning 6 . okt. 48.

Ad IV c: Et brev fra Johan Nordahl Brun til Gr. 21. marts 1815 er tr. i Personalhist. Tidsskr. 1947, 126 f., ved Bj. Kornerup. Jvf. hertil H. TopsøeJensen: Johan Nordahl Brun og N. F. S. Gr. Kirkehist. Samlinger 6. rk. VI (1948-50), $509 \mathrm{f}$.

Om Dines Pontoppidans forhold til Gr. (og grundtvigianismen), se P. G. Lindhardt: Præsten Dines Pontoppidan 1814-1879. Aarhus 1948, spec. $29 \mathrm{ff}$. (Acta Jutlandica XX). 
Ad IV d: Jorgen Jensen: Tanker omkring inkarnationen - fra et grundtvigsk synspunkt. - Lovet være du Jesus Krist. Inkarnationen. Seks Forelæsninger. Bringstrup 1949, 59-65.

Axel Riishøj: Gr. og det græsk-nordiske hedenskab. - Dansk Tunge 1946, 121-126. Hertil Johs. Lauridsen s. st. 1947, $17 \mathrm{f}$.

Ad IV e: C. P. O. Christiansen: Gr.s Historiesyn. - Tr. i »Menneskesyn og Historiesyn. Udg. af »Venner af Gr.s Göteborgtanke«.« Askov [1949], $31-36$.

C. J. Scharling: Gr. og Romantiken, 1947, ogsaa anmeldt af Johs. Lauridsen i Dansk Tunge 1947, 116-120, og af Sigvard Magnusson i Nord. Tidskr. 1950, 169-172.

H. Toldberg: Gr. som filolog, 1946, ogsaa anmeldt af P. M. Mitchell i Scandinavian Studies, Aug. 1951, $162 \mathrm{f}$.

Ad IV i: Axel Riishøj: Gr. og Sønderjylland. - Dansk Tunge 1948, 46-51. Ad IV l: Gustav Carstensen: Nordens profet. - Tr. i »Nordisk kristendom. Kristna gestalter från de nordiska länderna«. Red. av Hj. Lindroth. Sthlm. 1944, 134-156. Hertil A. Riishøj i Dansk Tunge 1945, 65-70.

Ad IV m: Axel Riishøj: Gr. og demokratiet. - Dansk Tunge 1949, 9-14.

Ad IV n: P. G. Lindhardt: Den nordiske kirkes historie, 1945.

Jorgen Begh: Grundtvigianismens Fremtid. - Information 24. april 48.

W. Michelsen: Gr. og Fremtiden. - Studenterkredsen, sept. 1948, 4-6.

Ad IV q: Om Gr.-Selskabets stiftelse se ogsaa Helge Toldberg i Ribe StiftsTidende 5. marts 48 .

Gr.-Studier 1948 ogsaa anmeldt af Sune Andresen i Dansk Tunge 1948, 115 og af E. J. i Göteborgs Handels- och Sjöfarts-Tidning 6. okt. 48.

Gr.-Studier 1949 ogsaa anmeldt anonymt i Dansk teol. Tidsskr. 1950, 61 og af N. J. R(ald) i Præsteforen.s Blad 21. okt. 49.

Rettelser til oversigten 1945-49.

Side 116, 1. 22 f. o.: $1951>1952$.

- 117, - 5 f. o.: kristelig > kristelige.

- $\quad$ - - 9 f. o.: $1950>1949$.

- 119, - 8 f. o.: $50>60$.

- 130, - 3 f. o.: Hedningsmissionen $>$ Hedningemissionen. 